\title{
Life insurance and genetic testing: Is genetic information an exception?
}

\section{Amanda Morgan}

\author{
University of Western Ontario
}

Many believe genetics may help us to personalize medicine and prevent negative health outcomes through earlier detection and prophylactic treatment. Advances in genetic technology have reduced the cost of genetic testing and Canadians are rapidly gaining greater access to their genetic information. However, as genetic testing becomes more prevalent, so does the call for specific policy to regulate the use of genetic data. In particular, the debate in Canada has centred on the use of genetic information by life insurance companies and has led some to ask:is genetic information exceptional? And should it be treated differently than other medical information? ${ }^{1}$

The case study below illustrates both the potential benefit and harm of genetic testing:

A young man with no symptoms underwent genetic testing for hemochromatosis, a disorder that causes the body to absorb too much iron. His result was positive but through early detection and prophylactic treatment he prevented the iron overload that can cause life threatening organ damage. Despite his good health and testimony from his doctor, he was denied life insurance. "Even though I have proven that I prevented health problems...they condemn me to the same category as a lost cause." ${ }^{\prime 2}$

Genetic discrimination (GD) is defined as discrimination arising from "the real or perceived genetic status of that individual."2 Fifty-two percent of Canadians fear their genetic information will be misused by third-parties ${ }^{3}$, including discrimination by insurers to increase premiums or deny coverage ${ }^{4}$. Seventy-one percent of those expressing significant concerns said their concerns "would likely effect their willingness to get genetic testing done." ${ }^{\prime 3}$ In Ontario, $39 \%$ of participants from the general population $(n=7173)$ agreed with the statement "Genetic testing is not a good idea because you might have trouble getting or keeping your insurance." ${ }^{\prime 4}$
Policymakers in many countries have been compelled by their constituents to enact laws that limit or ban the use of genetic information by third parties ${ }^{5,6}$. These laws serve two purposes ${ }^{6}$ :

1) To protect individuals from misuse of their genetic information.

2) To benefit society by promoting use of genetic testing in healthcare and research.

Currently, Canada is the only G7 country that does not have laws in place to protect citizens from misuse of their genetic information. In 2008, the United States (U.S.) enacted Genetic Information Nondiscrimination Act (GINA) to protect individuals from GD by health insurance companies and employers ${ }^{5}$. While it may be tempting to follow the example set by U.S. legislation, GINA does not address life insurance or barriers to research participation ${ }^{5,7}$. Canadians require legislation that is tailored to our own healthcare system and insurance products.

Life insurance applicants are not required to undergo genetic testing in Canada ${ }^{8}$. However, insurance companies may "request that existing genetic test results be made available", including results that are disclosed to research participants ${ }^{8}$. An insurance policy is a contract made between an insurance company and the insured ${ }^{8}$ with the purpose of providing financial security to surviving family members in the event of an unexpected death7 ${ }^{7}$. The Canadian Life and Health Insurance Association believes an insurance contract must be made in "good faith" and requires both parties to enter the agreement with equal knowledge ${ }^{8}$. Insurers feel that genetic information should be treated the same as other medical information (family history, lifestyle factors, health conditions) used for underwriting, which refers to assigning an individual to a risk group ${ }^{9}$. 
The process of underwriting is inherently discriminative; for example, men often pay higher premiums than women. Since individuals with higher risk usually pay a higher premium, it is not uncommon for applicants to try to hide information and purchase larger policies? ${ }^{7}$. This can lead to the insurance company charging the insured less for the policy and paying out more when the insured dies: a situation known as adverse selection that can lead insurance companies to become unsustainable or to increase premiums. Recent studies have suggested that Canadian insurance companies are not likely to experience significant negative impact if genetic information use was banned ${ }^{9,10}$. However, it is recommended that policymakers reassess the economic impact of any laws enacted to ensure that insurance remains affordable for all Canadians ${ }^{9,10}$.

Although from a legal perspective genetic information may not be truly exceptional, Canadians feel their genetic information should be treated differently. The perceived risk of GD affects health choices and deters participation in research that may improve healthcare for the future. This suggests laws are needed to relieve the "fear" of GD. Ideally, Canadian legislation should aim to reduce fear of $\mathrm{GD}$, promote the use of genetics, and prevent significant adverse selection. This might be achieved by only granting insurers access to genetic information for policies over a threshold value.

\section{References}

1. Hellman D. What makes genetic discrimination exceptional? Am J law Med. 2003;29:77-116.

2. Billings PR, Kohn MA, de Cuevas M, Beckwith J, Alper JS, Natowicz MR. Discrimination as a consequence of genetic testing. Am J Hum Genet. 1992;50(3):476-82.

3. Canada. Phoenix Strategic Perspectives. Survey of Canadians on PrivacyRelated Issues. Ottawa; 2013.

4. Hall MA, McEwen JE, Barton JC, Walker AP, Howe EG, Reiss JA, et al. Concerns in a primary care population about genetic discrimination by insurers. Genet Med. 2005;7(5):311-6.

5. Joly Y, Ngueng Feze I, Simard J. Genetic discrimination and life insurance: a systematic review of the evidence. BMC Med. 2013;11:25.

6. Hall MA, Rich SS. Genetic privacy laws and patients' fear of discrimination by health insurers: the view from genetic counselors. J Law Med Ethics. 2000;28:245-57.

7. Knoppers BM, Lemmens T, Godard B, Joly Y, Avard D, Clark T, et al. Genetics and life insurance in Canada: Points to consider. Can Med Assoc J. 2004;170(9):1-3.

8. Canadian Life and Health Insurance Association. Industry code : genetic testing information for insurance underwriting. 2014.

9. Macdonald $A$. The actuarial relevance of genetic information in the life and health insurance context. Ottawa; 2011.

10. Hoy M, Durnin M. The potential economic impact of a ban on the use of genetic information for life and health insurance. 2012.

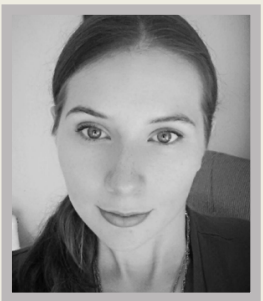

Amanda Morgan

Amanda Morgan is currently pursuing her MSc. in Health and Rehabilitation Sciences (Hearing Science) at the University of Western Ontario. She received an honours BSc at the University of Western Ontario in 2014. Her research focuses on genetics of hereditary hearing loss and physiological measurements of the auditory phenotype. She is also interested in knowledge translation of genetics research to genetic counsellors, medical practitioners, and patients. 